\title{
Laboratory Evaluation of the Toxicity of Acetamiprid and Sulfoxaflor Against the Red Palm Weevil Rhynchophorus ferrugineus (Olivier)
}

\author{
Saleh S. Alhewairini \\ Department of Plant Production and Protection, College of Agriculture and Veterinary \\ Medicine, Qassim University, P.O. Box 6622, Buraidah 51452, Qassim, Saudi Arabia.
}

\begin{abstract}
A B S T RA C T
The red palm weevil (RPW), Rhynchophorus ferrugineus Olivier, is becoming a real threat to date palm trees in different locations of Saudi Arabia.Therefore, control and management of RPW have gained the attention of government as well as private concerns. In this study, the toxicity of acetamiprid and sulfoxaflor on RPW was evaluated under laboratory conditions. RPW (larvae and adult) showed high susceptibility to both acetamiprid and sulfoxaflor. In addition, both insecticides had significant effect on the mortality of RPW (larvae and adult) except the pupal stage under laboratory conditions. After direct spray application of the recommended dose, the adult mortality percentages were $66.67,73.33$ and $100 \%$ for acetamiprid and 23.33, 60 and $96.67 \%$ for sulfoxaflor after 1, 24, and $48 \mathrm{~h}$, respectively, whereas the larvae mortality percentages were $63.33,73.33$ and $100 \%$ for acetamiprid and $46.67,73.33$ and $96.67 \%$ for sulfoxaflor after 1, 24, and $48 \mathrm{~h}$, respectively. Moreover, live RPW (larvae and adult) were found to be completely paralyzed after $24 \mathrm{~h}$ of exposure to both insecticides. Statistically, the difference between 1, 24 and $48 \mathrm{~h}$ in both adult and larvae at both application (direct spray or soaked palm tissue (contact/ ingestion)) was significant ( $\mathrm{p}<0.05)$ except the for difference between $1 \mathrm{~h}$ and 24 hin larvae with direct spray treatment, which was insignificant $(\mathrm{p}>0.05)$. The study concludes that new information regarding the efficacy of these two insecticides which can be used to replace the conventional, over-aged and less effective insecticides that have been extensively used in controlling RPW.
\end{abstract}

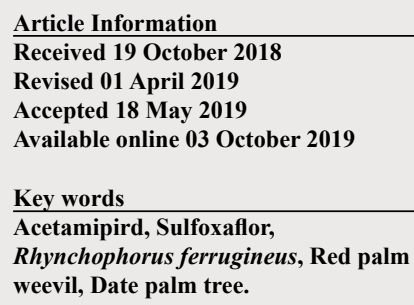

\section{INTRODUCTION}

$I^{n}$ n Saudi Arabia, there were over 18 million date palm trees in 2004 (Anonymous, 2004) and more than 28 million in 2015 (General Authority for Statistics, KSA, 2015). The Qassim region (center of Saudi Arabia) has approximately $24 \%$ ( 7 million) of these palm trees. The significant increase of 10 million date palm trees between 2004 and 2015, shows their economic importance. Like other plants, the date palm tree is attacked by variety of pests which can limit their development as well as their production. Among these pests, the red palm weevil (RPW), Rhynchophorus ferrugineus (Olivier) is the most dangerous.

The RPW infestation has spread rapidly in the middle east region since 1980 (Gomez and Ferry 1999). The RPW infestation has been in Saudi Arabia in 1987 (Abraham et al., 1998), Egypt in 1992 (Cox, 1993), Spain in 1994

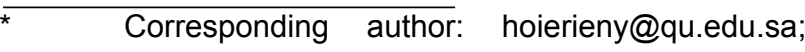
ssalhowirini@yahoo.com 0030-9923/2020/0055-0001 \$ 9.00/0

Copyright 2020 Zoological Society of Pakistan
}

(Barranco et al., 1996), Iran in 1996 (Faghih, 1996), Jordan and Palestine in 1999 (Kehat, 1999), and the United Arab Emirates in 1985 (Zaid et al., 2002).

RPW is considered as the most destructive pest for date palm trees. RPW inflict considerable damage to palm's trunk, that weakens the trunk resulting in poor growth and makes the trunk less resistant to environmental conditions (e.g. strong winds) and ultimately leads to reduced yield. In reaction to the RPW threat, several countries have launched programs with major funding in order to manage and control RPW. One example is California, which spends approximately 70 million US dollars annually on ornamental palms (Hussain et al., 2013). Likewise, Saudi Arabia spent about 450 million US dollars for a five-year program to control RPW infestation of date palm trees. Finally, an estimated loss of $30 \%$ in global date production occurred due to RPW infestation in the Arabian Peninsula (El-Sabea et al., 2009).

Control and management of RPW is extremely difficult because infestation cannot be easily detected or diagnosed in the early stage because the RPW remains inside, feeding upon and damaging the trunk without any 
external symptoms. In a year, three complete life cycles have been reported by Hussain et al. (2013) from Saudi Arabia. Though it is difficult, but timely diagnosis of infestation at an early stage can save the palm tree whereas late detection can lead to serious damage or complete loss of the palm tree. The RPW infestation symptoms include detectable tunnels in the trunk, a thick yellow fluid oozing from the palm, empty pupal cases, external entrance, and toppling of the crown (Hussain et al., 2013; Abo-El-Saad et al., 2013). All of these symptoms show that there is a serious damage to the palm tree.

Since 1998, researchers have used several methods under integrated pest management (IPM) to control infestation, such as pheromone traps, surveillance and inspection, chemical control and cultural control (Abraham et al., 1998; Shawir et al., 2014). However, widespread usage of insecticides in different ways is still the chief method used to eradicate RPW. Insecticides are being used as soil treatment, frond axil filling, trunk injections, tree fumigation, crown drenching, wound dressing and dipping offshoots (Hussain et al., 2013; Al-Shawaf et al., 2013). Therefore, chemical control is still the main option for date palm growers to suppress the spread of RPW. The spread of RPW around the world has encouraged researchers to focus their strategies on its management. The effects of three insecticides, carbosulfan, pirimiphos-ethyl and rogodial, on all stages of RPW infestation was evaluated in a UAE laboratory (El-Ezaby, 1997). The UAE laboratory results showed that these three insecticides had high mortality on all stages of RPW. In Saudi Arabia, during the last two decades, a large number of laboratory experiments have been carried out in order to evaluate and test the sensitivity of RPW to a wide range of insecticides. These insecticides belong to different groups such as carbamate, organophosphate, organochlorine, phenylpyrazole, neonicotinoid and macrocyclic lactone (Abraham et al., 1998; Ajlan et al., 2000; Abo-El-Saad et al., 2001; AlRajhi et al., 2005; Al-Shawaf et al., 2010; Abo-El-Saad et al., 2011; Al-Jabr et al., 2013). Insecticides which have been tested in other laboratories and/or in field experiments worldwide include spirotetramat, azadirachtin, aluminum phosphide, methidathion and oxamyl against all stages of RPW (Cabello et al., 1997; Kaakeh, 2006; Llacer and Jacas, 2010; Shar et al., 2012; Shawir et al., 2014; Alhewairini, 2018).

In the present study, the efficacy of two systemic insecticides acetamiprid and sulfoxaflor was tested against RPW. Acetamiprid belongs to the family of chloropyridinyl neonicotinoids. It has been extensively used under several trade names such as Assail and Chipco to control sucking insects in several crops such as citrus fruits, leafy vegetable, cotton, ornamental plants and grapes.
Sulfoxaflor belongs to the sulfoximines class of insecticides. It is sold under several trade names such as Closer and Tranform for controlling piercing/sucking insects such as plant bugs, aphids, thrips and stink bugs in different type of crops.

Both acetamipird and sulfoxaflor act as agonists of nicotinic acetylcholine receptors (nAChR).

Thus, the purpose of this study is to evaluate the efficacy of acetamipird and sulfoxaflor against RPW (adults, larvae and pupae) under laboratory conditions.

\section{MATERIALS AND METHODS}

\section{Insects}

All stages of RPW, including adults (males and females), larvae and pupae, were collected from a date palm farm that was recently infected by RPW (without being treated by any insecticides) in the north of AlQassim region.

\section{Solutions and experimental protocol}

Acetamiprid (Mosprid 20\% SL, acetamiprid) was procured from Erzam Company. Sulfoxaflor (Closer 240 SC, sulfoxaflor) was obtained from Twaiq Agriculture Company. Only the recommended application rates were tested using $50 \mathrm{ml} / 100 \mathrm{~L}(100 \mathrm{ppm})$ and $43 \mathrm{ml} / 100 \mathrm{~L}$ (103.2ppm) for acetamiprid and sulfoxaflor, respectively.

The recently RPW-infested and non-treated farm was chosen (in the city of Al-Bukairyah, Al-Qassim, Saudi Arabia) to collect all required stages of RPW in this study to ensure no other factors could influence the toxicity of the insecticides being tested. All stages of RPW were collected from inside the trunk of the infested palm tree to ensure that they have not been exposed to any other insecticides while they were moving around especially the adults. Thereafter, the collected RPW were placed separately in a clean plastic container and transferred immediately to the laboratory $\left(25 \pm 2^{\circ} \mathrm{C}\right.$ and $70 \%$ relative humidity) at the Department of Plant Production and Protection, College of Agriculture and Veterinary Medicine, Qassim University and used to perform bioassays immediately after collection. In the first set of experiments, seven adults and 7 larvae with three replicates (42 RPW in total) were placed in a plastic container with palm wood pieces as a source of food. Thereafter, they were exposed directly to acetamiprid, sulfoxaflor and distilled water (without insecticides) as a control with the use of a conventional hand sprayer (1L).

In a second set of experiments, the palm wood pieces were soaked in insecticide solutions. The palm wood pieces were peeled, to make them more attractive to RPW, and soaked for $1 \mathrm{~min}$ in spray solution of acetamiprid, 
sulfoxaflor and distilled water as control. Then, they were left to dry on clean tissue paper. Dried peeled palm tissues were subsequently placed in plastic containers. Thereafter, seven adults and seven larvae were released to the container to feed on treated palm wood pieces. The experiments were repeated three times. The adults and larvae were kept starved $12 \mathrm{~h}$ before the start of experiment, so that they were likely to eat palm wood during the experiment for better result. The mortality rate was noted after 1, 24 and $48 \mathrm{~h}$ by applying a gentle touch using a glass rod to count dead and/or paralyzed RPW and recording them as a percentage of mortalities.

\section{Statistical analysis}

The mortality of RPW was determined manually by direct observation. Collected data was processed using Microsoft Excel. The collected data for all variables were statistically analyzed using the MSTATC microcomputer program (MSTATC, 1990). The least significant difference (LSD) test was used to compare the mean mortality percentages. Only differences significant at $\mathrm{P} \leq 0.05$ are considered in the text. Each value indicated the mean mortality percentage \pm SEM of each treatment.

\section{RESULTS}

The efficacy of acetamiprid and sulfoxaflor against RPW (larvae, adults and pupae) was evaluated under laboratory conditions. RPW (larvae and adults) showed high susceptibility to both acetamiprid and sulfoxaflor. The mortality percentages were associated with an increase in the time of exposure. This includes observable reduction in the mobility of RPW (larvae and adults) after application of both insecticides. RPW (larvae, adult and pupae) were exposed to acetamiprid and sulfoxaflor by two different applications (direct spray and soaked palm tissue (contact/ ingestion)). In response to direct spray application, the adult mortality percentages were $66.67,73.33$ and $100 \%$ for acetamiprid and 23.33, 60 and $96.67 \%$ for sulfoxaflor after 1, 24 and $48 \mathrm{~h}$, respectively, whereas the larvae mortality percentages were $63.33,73.33$ and $100 \%$ for acetamiprid and 46.67, 73.33 and $96.67 \%$ for sulfoxaflor after 1,24 , and $48 \mathrm{~h}$, respectively, compared with $0 \%$ mortality rate in the control (distilled water) (Table I). In the soaked palm tissue (contact/ingestion) application, the adult mortality percentages were $0.0,56.67$ and $96.67 \%$ for acetamiprid and 0,30 and $70 \%$ for sulfoxaflor after 1 , 24 , and $48 \mathrm{~h}$, respectively, whereas the larvae mortality percentages were $0.0,76.67$ and $100 \%$ for acetamiprid and $0.0,43.33$ and $83.33 \%$ for sulfoxaflor after 1,24 , and 48 h, respectively (Table I). Furthermore, live RPW (larvae and adults) were found completely paralyzed after $24 \mathrm{~h}$ of exposure to both insecticides, as they only can show the intermittent motion after applying a gentle touch. Statistically, the difference between 1, 24 and $48 \mathrm{~h}$ in both adult and larvae at both applications was significant $(\mathrm{p}<$ 0.05 ) except for the difference between $1 \mathrm{~h}$ and $24 \mathrm{~h}$ in larvae in response to direct spray application $(p>0.05)$ (Table I). Moreover, there was no significant difference after $72 \mathrm{~h}$ of exposure between acetamiprid and sulfoxaflor as there was $100 \%$ mortality in both adults and larvae in both cases.

Table I. The mortality percentage of adults and larvae of RPW after 1, 24 and $48 \mathrm{~h}$ of exposure to acetamiprid and sulfoxaflor (direct spray and soaked palm pieces).

\begin{tabular}{|c|c|c|c|c|c|}
\hline \multirow[b]{2}{*}{ Treatments } & \multicolumn{2}{|c|}{ Acetamiprid } & \multicolumn{2}{|c|}{ Sulfoxaflor } & \multirow[b]{2}{*}{ Mean of time } \\
\hline & Direct spray & Contact/ingestion & Direct spray & Contact/ingestion & \\
\hline \multicolumn{6}{|l|}{ Adults } \\
\hline $1 \mathrm{~h}$ & $66.67 \pm 2.58$ & $0.00 \pm 0.00$ & $23.33 \pm 4.47$ & $0.00 \pm 0.00$ & $22.5 \mathrm{c}$ \\
\hline $24 \mathrm{~h}$ & $73.33 \pm 2.58$ & $56.67 \pm 5.16$ & $60.00 \pm 0.00$ & $30.00 \pm 5.16$ & $55.00 \mathrm{~b}$ \\
\hline $48 \mathrm{~h}$ & $100 \pm 0.00$ & $96.67 \pm 2.58$ & $96.67 \pm 5.16$ & $70.00 \pm 0.00$ & $90.38 \mathrm{a}$ \\
\hline Mean of methods & $80.00 \mathrm{a}$ & $51.1 \mathrm{~b}$ & $60.00 \mathrm{~b}$ & $33.3 \mathrm{c}$ & \\
\hline \multicolumn{6}{|l|}{ Larvae } \\
\hline $1 \mathrm{~h}$ & $63.33 \pm 5.16$ & $0.00 \pm 0.00$ & $46.67 \pm 2.58$ & $0.00 \pm 0.00$ & $32.00 \mathrm{c}$ \\
\hline $24 \mathrm{~h}$ & $73.33 \pm 2.58$ & $76.67 \pm 2.58$ & $73.33 \pm 5.16$ & $43.33 \pm 2.58$ & $66.67 \mathrm{~b}$ \\
\hline $48 \mathrm{~h}$ & $100 \pm 0.00$ & $100 \pm 0.00$ & $96.67 \pm 2.58$ & $83.33 \pm 5.16$ & $95.00 \mathrm{a}$ \\
\hline Mean of methods & $21.11 \mathrm{a}$ & $25.56 \mathrm{a}$ & $32.22 \mathrm{a}$ & $27.78 \mathrm{a}$ & \\
\hline
\end{tabular}

LSD $0.05=11.23$, Time X methods; a-c means within time or method followed by the same letter are not significantly different $(\mathrm{P}=0.05)$. 
Acetamiprid appeared to be more efficacious than sulfoxaflor as it could produce $100 \%$ mortality in both the adult and larvae of RPW. However, both insecticides have not shown any effect on pupae of RPW as there was no mortality as well as there was no effect on mobility and all treated pupae were found alive.

\section{DISCUSSION}

In different locations of Saudi Arabia, date palm tree growers have complained about the lower efficacy of the most available insecticides in the market, such as pyrthroids and imidacloprid. They have also reported that the RPW has become less susceptible to these insecticides as they became ineffective at the recommended dose. This might force many growers to exceed the recommended dose to achieve the highest mortality to suppress the spread of RPW. The extensive use and misuse of insecticides can lead to the building up of resistance in RPW which may make it difficult to control. Nevertheless, RPW infestation is still recoded in new locations which have never been infested by RPW in the past. Moreover, there are governmental and public concerns about the misuse of insecticides in controlling RPW as it will result in an increase of residual effects and toxicity to non-target species (e.g. beneficial insects, predatory insects and mites). Therefore, this study was designed to evaluate the toxicity of acetamiprid and sulfoxaflor on RPW under laboratory conditions. Being systemic insecticides both acetamiprid and sulfoxaflor can be utilized in controlling RPW, as RPW feeds and completes its life cycle inside the trunk of the date palm. This makes non-systemic insecticides useless as they cannot reach all stages of RPW inside the trunk. RPW (adult and larvae) were susceptible to acetamiprid and sulfoxaflor as they could produce significant toxic effects on RPW (adult and larvae). The obtained results showed that acetamiprid and sulfoxaflor can cause a decline in the population of RPW. A marked reduction in the mobility of RPW (adult and larvae) was seen immediately after direct application of both insecticides which resulted in complete paralysis. Nevertheless, acetamiprid seems to be more toxic to all tested stages of RPW (adult and larvae) than sulfoxaflor, although they have the same mode of action (agonist of nAChR). Moreover, only acetamiprid could produce $100 \%$ mortality of RPW (adult and larvae) after $48 \mathrm{~h}$ of direct exposure to the recommended dose compared with sulfoxaflor.

On the other hand, both insecticides had no effect on the mortality of RPW after $1 \mathrm{~h}$ of exposure to soaked palm tissue (contact/ingestion).

Acetamiprid and sulfoxaflor, however, had no effects on the pupae of RPW as adults emerging from pupae were found alive without any effect on their mobility compared with control. This might be because both insecticides cannot permeate inside the pupae, as it is protected by its cocoon and does not feed.

Acetamiprid and sulfoxaflor cannot cause a rapid death of RPW (adult and larvae) compared with oxamyl, for example, as Alhewairini (2018) found that oxamyl can cause a rapid death of RPW (adult and larvae) and 100\% mortality was achieved $24 \mathrm{~h}$ after exposure. Clearly, both acetamiprid and sulfoxaflor require a prolonged time of exposure to cause 100\% mortality of RPW (adult and larvae). Therefore, it would also be assumed that their efficacy might be influenced by other environmental factors, especially when these insecticides are applied in an open field.

Higher concentrations of acetamiprid and sulfoxaflor may effectively increase their efficacy against RPW, but this can add further environmental and health contamination risk as dates are consumed immediately after picking or kept in cool storage, which can cause a delay in insecticides degradation. Therefore, with such application several environmental and health impacts must be taken into a consideration.

\section{CONCLUSION}

Laboratory experiments have provided new information regarding the toxicity of acetamiprid and sulfoxaflor on adult and larvae of RPW which can be used in the control program of RPW. Both insecticides were found to be significantly toxic to RPW (adult and larvae) after exposure at their recommended doses by either direct spray or soaked palm tissue (contact/ingestion). Furthermore, both insecticides were found ineffective against pupae as they were found alive after exposure. Therefore, it would be interesting to investigate the potential efficacy of both insecticides for use in the openfield applied as direct spray, offshoots dipping, and trunk injection, which might successfully help in minimizing the infection as well as spread of RPW.

\section{ACKNOWLEDGEMENT}

The author acknowledged the financial funding by Saleh Kamel Chair for Date Palm Research (SKCDR), Qassim University. The author is grateful to Dr. Mohamed Motawei and Dr. Mohammad Al-Deghairi for revising this manuscript.

\section{Statement of conflict of interest}

The author declares no conflict of interest. 


\section{REFERENCES}

Abraham, V.A., Al-Shuaibi, M., Faleiro, J.R., Abozuhairah, R.A. and Vidyasagar, P.S.P.V., 1998. An integrated approach for the management of red palm weevil Rhynchophorus ferrugineus Olivier. A key pest of date palm in the Middle-East. Sultan Qaboos Univ. J. scient. Res. Agric. Sci., 3: 77-83. https://doi.org/10.24200/jams.vol3iss1pp77-83

Abo-El-Saad, M.M., Ajlan, A.M., Shawir, M.S., AbdulSalam, K.S. and Rezk, M.A., 2001. Comparative toxicity of four pyrethroid insecticides against red palm weevil, Rhynchophorus ferrugineus (Olivier) under laboratory conditions. J. Pest Contr. environ. Sci., 9: 63-76.

Abo-El-Saad, M.M., Elshafie, H.A., Faleiro, J.R. and Bou-Khowh, I.A., 2011. Toxicity evaluation of certain insecticides against the red palm weevil, Rhynchophorus ferrugineus (Olivier), under laboratory conditions. ESA Annual Meeting.

Abo-El-Saad, M.M., Elshafie, H.A. and BouKhowh, I.A., 2013. Toxicity of bio-insecticide, Abamectin,on red palm weevil, Rhynchophorus ferrugineus(Olivier). Int. J. agric. Sci., 2: 107-115.

Ajlan, A.M., Shawir, M.S., Abo-El-Saad, M.M. and Rezk, M.A., 2000. Laboratory evaluation of certain organophosphorus insecticides against the red palm weevil, Rhynchophorus ferrugineus (Olivier). J. Basic appl. Sci., 1: 119-130.

Al-Ayedh, H., Hussain, A., Rizwan-ul-Haq, M. and AlJabr, A.M., 2015. Status of insecticide resistance in field-collected populations of Rhynchophorus ferrugineus (Olivier) (Coleoptera: Curculionidae). Int. J. agric. Biol., 18: 103-110. https://doi. org/10.17957/IJAB/15.0070

Alhewairini, S.S., 2018. Laboratory and field evaluation of the toxicity of oxamyl against the red palm weevil, Rhynchophorus ferrugineus (Olivier). Pakistan J. Zool., 50: 249-256. http://dx.doi. org/10.17582/journal.pjz/2018.50.1.249.256

Al-Jabr, A.M., Rizwan-ul-Haq, M., Hussain, A., Al-Mubarak, A.I. and Al-Ayed, H.Y., 2013. Establishing midgut stem cell culture from Rhynchophorus ferrugineus (Olivier) and toxicity assessment against 10 different insecticides. In Vitro Cell Develop. Biol. Anim., 50: 296-303. https://doi.org/10.1007/s11626-013-9694-1

Al-Rajhi, D.H., Hussein, H.I. and Al-Shawaf, A.M.A., 2005. Insecticidal activity of carbaryl and its mixture with piperonylbutoxide against the red palm weevil, Rhynchophorus ferrugineus (Olivier) (Coleoptera: Curculionidae) and their effects on acetylcholinesterase activity. Pakistan J. biol. Sci., 8: 679-682. https://doi.org/10.3923/ pjbs.2005.679.682

Anonymous, 2004. The fruit of the desert. Saudi Date Market, AI-Butain Agricultural Cooperative Association (BACA), Issue June 7.

Al-Shawaf, A.M., Al-Shagagh, A.A., Al-Bakshi, M.M., Al-Saroj, S.A., Al-Badr, S.M., Al-Dandan, A.M. and Abdallah, A.B., 2010. Toxicity of some insecticides against red palm weevil Rhynchophorus ferrugineus (Coleoptera: Curculionidae). Indian J.Pl. Protec., 38: 13-16.

Al-Shawaf, A.M., Al-Shagag, A., Al-Bagshi, M., Al-Saroj, S., Al-Bather, S., Al-Dandan, A.M., Abdallah, A.B. and Faleiro, J.R., 2013. A quarantine protocol against red palm weevil Rhynchophorus ferrugineus (Olivier) (Coleoptera: Curculionidae) in date palm. J. Pl. Protec. Res., 53: 409-415. https://doi.org/10.2478/jppr-2013-0061

Barranco, P., Pena, D.L.J. and Cabello, T., 1996. A new tropical curculionid for the European fauna, Rhynchophorus ferrugineus (Olivier, 1790), (Coleoptera: Curculionidae). Bol. Asoc. Espan. Ent., 20: 257-258.

Cabello, T., Pena, J.D.L., Barranco, P. and Belda, J., 1997. Laboratory evaluation of imidacloprid and oxamyl against Rhynchophorus ferrugineus. TestsAgrochem. Cult. U.K., 18: 6-7.

Cox, M.L., 1993. Outbreaks and new records: Egypt: Red palm weevil, Rhynchophorus ferrugineus, in Egypt. FAO (Food and Agriculture Organization of the United Nations). Pl. Protec. Bull., 41: 30-31.

El-Sabea, A.M.R., Faleiro, J.R. and Abo-El-Saad, M.M., 2009. The threat of red palm weevil Rhynchophorus ferrugineus to date plantations of the Gulf region of the Middle East: An economic perspective. Outlook Pest Manage., 20: 131-134. https://doi.org/10.1564/20jun11

Faghih, A.A., 1996. The biology of red palm weevil, Rhynchophorus ferrugineus Oliv. (Coleoptera: Curculionidae) in Saravan region (Sistan and Balouchistan Province, Iran). Appl. Ent. Phytopathol., 63: 16-18.

General Authority for Statistics, 2015. Agriculture census. Kingdom of Saudi Arabia. Available at:http://www.stats.gov.sa/agri/indexeng.html

Gomez, V.S. and Ferry, M., 1999. Attempts at biological control of date palm pests recently found in Spain. In: Proceedings of the first regional symposium for applied biological control in Mediterranean Countries (eds. M. Canard and V. Beyssatarnaouty). Cairo, 25-29 October 1998. 
Imprimerie Sacco,Toulouse, France, pp. 121-125.

Hussain, A., Rizwan-ul-Haq, M., Al-Jabr, A.M. and AlAyied, H.Y., 2013. Managing invasive populations of red palm weevil: A worldwide perspective. $J$. Fd. Agric. Environ., 11: 456-463.

El-Ezaby, F., 1997. A biological in-vitro study on the Red Indian date palm weevil. Arab J. Pl. Protec.,15: 84-87.

Kaakeh, W., 2006. Toxicity of imidacloprid to developmental stages of Rhynchophorus ferrugineus (Curculionidae: Coleoptera): Laboratory and field tests. Crop Protec., 25: 432439. https://doi.org/10.1016/j.cropro.2005.07.006

Kehat, M., 1999. Threat to date palms in Israel, Jordan and the Palestinian authority by the red palm weevil, Rhynchophorus ferrugineus. Phytoparasitica, 27: 241-242. https://doi.org/10.1007/BF02981465

Llacer, E. and Jacas, J.A., 2010. Efficacy of phosphine as a fumigant against Rhynchophorus ferrugineus (Coleoptera: Curculionidae) in palms. Spanish J. agric. Res., 8: 775-779. https://doi.org/10.5424/ sjar/2010083-1278

Mstatc, A., 1990. Microcomputer program for the design, Management and analysis of agronomic research experiments. Michigan State University, East Lansing, MI, USA.

Shawir, M.S., Abbassy, M.A. and Salem, Y.M., 2014. Laboratory evaluation of some insecticides against larval and adult stages of Red Palm Weevil, Rhynchophorus ferrugineus (Olivier). Alexandria Sci. Exch. J., 35: 75-79. https://doi.org/10.21608/ asejaiqjsae.2014.2579

Shar, M.U., Rustamani, M.A., Nizamani, S.M. and Bhutto, L.A., 2012. Red palm weevil (Rhynchophorus ferrugineus Olivier) infestation and its chemical control in Sindh province of Pakistan. Afr. J. agric. Res., 7: 1666-1673. https:// doi.org/10.5897/AJAR11.896

Zaid, A., Wet, D.P.F., Djerbi, M. and Oihabi, A., 2002. Diseases and pests of date palm (Chapter XII). In: Date palm cultivation (ed. A. Zaid). FAO Plant Prod. Prot Paper 156, Rome, Italy, pp. 227-281. 